\title{
Prevalence and Its Associated Factors to Diarrhea Among Under Five Children in Ethiopia
}

\author{
Yenew Alemu Mihret \\ Department of Statistics, College of Natural and Computational Science, Injibara University, Injibara, Ethiopia \\ Email address: \\ yenewalemu@gmail.com

\section{To cite this article:} \\ Yenew Alemu Mihret. Prevalence and Its Associated Factors to Diarrhea Among Under Five Children in Ethiopia. Mathematics Letters. \\ Vol. 6, No. 3, 2020, pp. 32-35. doi: 10.11648/j.ml.20200603.11
}

Received: September 1, 2020; Accepted: September 23, 2020; Published: November 16, 2020

\begin{abstract}
Diarrhea is defined as having three or more loose, or liquid stools per day. Ethiopia is one of the developing subSaharan African countries sharing the high burden of diarrhea mortality. The risk of a child dying before becoming the age of under-five children was highest in Ethiopia as well as in the world. The aim of the study was to assess the prevalence and factors associated with diarrhea among children of age of under-five in Ethiopia. This study used data from the 2016 Ethiopia demography and health survey. The prevalence of diarrhea among under-five children was 825 children out of 5,335 in Ethiopia. Based on the chi-square test; region, currently pregnant mothers, child lives with whom and source of drinking water were significantly associated with the prevalence of diarrhea among the ages of under-five children. Binary logistic regression was applied and analyzed using Stata version 14. Region, child living with whom and source of water are the significant factor of the prevalence of diarrhea under five children. A child taking protected water, and a child living with his or her family is highly appreciated for reducing the prevalence of diarrhea among the ages of under-five children. In addition, planning for better access to health facilities for each region.
\end{abstract}

Keywords: Diarrhea, Prevalence, Risk Factors, Under Five Children, Ethiopia

\section{Introduction}

Diarrhea is defined as having three or more loose, or liquid stools per day [1]. Diarrhea disease is the cause of the death of under-five children, every year globally killing around 760 , 000 children and more than $90 \%$ results from contaminated food and water sources in the world $[2,3]$ and children under the age of five has been high risk living in low and middleincome countries [4].

The risk of a child dying before becoming the age of under-five children was highest in the World health organization African Region (90 per 1000 live births), which is approximately seven times higher than that in the World health organization European Region (12 per 1000 live births) [5]. Of the estimated total of 10.6 million deaths among children younger than five years of age worldwide, $42 \%$ occurred in the African region due to diarrhea and others diseases $[6,7]$.

Ethiopia is one of the developing sub-Saharan African countries sharing the high burden of diarrhea mortality. The incidence of illnesses contributing to avoidable death's diarrhea is higher in Ethiopia compared to other Sub Saharan African countries partly due to living conditions, high incidence of illness, lack of safe drinking water, sanitation, and hygiene; as well as poorer overall health and nutritional status $[2,8,9]$.

Twelve percent of children under five had diarrhea two weeks before the survey. More than four out of 10 children under five $(44 \%)$ who had diarrhea sought treatment. The diarrhea rate is still high, it continues to be a burden to Ethiopia population and diarrhea is the main problem not only the age of under-five children but also for all populations [10]. Therefore, the study aims were to assess the prevalence and risk factors of diarrhea among under-five children in Ethiopia.

\section{Methods}

\subsection{Source of Data}

This study used data from the 2016 Ethiopia demography and health survey. 


\subsection{Variables}

The dependent variable is diarrhea disease status or occurrence of diarrhea among the ages of under-five children and explanatory variables are region, types of place of residence, source of drinking water, ages of households, currently pregnant of mothers, a child lives with whom, types of toilet facility.

\subsection{Binary Logistic Regression Model}

Binary logistic regression is used for this study when the dependent variables are dichotomous [11]. The error terms are not normally distributed [12]. The logistic regression model is given as:

$$
\pi(x)=\frac{\exp \left(\beta_{0}+\beta_{1} X_{1}+\beta_{2} X_{2}+\cdots+\beta_{m} X_{m}\right)}{1+\exp \left(\beta_{0}+\beta_{1} X_{1}+\beta_{2} X_{2}+\cdots+\beta_{m} X_{m}\right)}
$$

Maximum likelihood estimator is used to estimate the parameter of the model [13] and Hosmer-Lemeshow test also available for model adequacy test.

\section{Results and Discussion}

\subsection{Results}

The prevalence of diarrhea among under-five children was 825 children out of 5,335 in Ethiopia. Based on the chisquare test; region, currently pregnant mothers, child lives with whom and source of drinking water were significantly associated with the prevalence of diarrhea among the ages of under-five children (Table 1). According to HosmerLemeshow goodness-of-fit test statistic ( $p$ value $=0.055)$ is greater than 0.05 , we conclude that the model is adequate.

Based on table 2, the expected value of the occurrence of diarrhea among under-five children from Amhara, Oromia, and Southern nations, nationalities, and people's region were $0.47,0.77$ and 0.72 times lower than the occurrence of diarrhea among the ages of under-five children in Tigray, respectively.

When we look at the source of drinking water, the odds of the occurrence of diarrhea among under-five children was 0.78 times lower than children taking protected water as compared to unprotected water.

Table 2 shows that the odds of the prevalence of diarrhea among the ages of under-five children from a child's lives with others were 5.95 times higher than the occurrence of diarrhea for the child lives with the respondents (his or her family).

\subsection{Discussion}

This study identified the risk factors associated with diarrhea among under-five children in the study area using the 2016 Ethiopia demography and health survey. This study indicated that the prevalence of diarrhea was observed in the Tigray region, $7.8 \% \%$ followed by Southern nations, nationalities, and people's region, Amhara and Oromia regions, 2.9\%, 2.8\%, and
$1.8 \%$, respectively. The odds of the occurrence of diarrhea among the ages of under-five children from Amhara, Oromia, and Southern nations, nationalities, and people's regions were less than as comparing to the Tigray region. This is inconsistent with findings from other studies [5, 14].

Another predictor variable of diarrhea found in this study was the source of drinking water. The present study found that the odds of diarrhea diseases of children for taking protected water were lower than unprotected (unsafe) water. This study is consistent with in Ethiopia $[5,15,16]$. Another study in sub-Saharan African [17], Indonesia [18] and Malaysia [19] also stated that the prevalence of diarrhea among the ages of under-five children for taking unprotected water is higher than drinking protected water.

According to the results of this study, it was found that the odds of prevalence of diarrhea in child lives with others were higher than that of children live his or her families. This may be due to misconception, and the negative attitude of the caregivers toward the causes of diarrhea. A study conducted in Ethiopia found that children living with others were more likely to the prevalence of diarrhea as compared to children living with the respondents [20]. Another study in Kenya [21] and Nigeria [22] also found that children living with others were at a high risk for the prevalence of diarrhea.

\section{Conclusion}

This study used data from the 2016 Ethiopia demography and health survey. Region, child lives with whom and source of drinking water were statistically significant factors for the prevalence of diarrhea under the age of under-five children. A child taking protected water, and a child living with his or her family is highly appreciated for reducing the prevalence of diarrhea among the ages of under-five children. In addition, planning for better access to health facilities for each region.

\section{Ethics Approval and Consent to Participate}

Ethical clearance for the 2016 EDHS was provided by the Ethiopian Health and Nutrition Research Institute Review Board, the National Research Ethics Review Committee at the Ministry of Science and Technology, the Institutional Review Board of ICF International, and the communicable disease control. Additionally, written consent for participation was obtained from each respondent. However, the dataset of the 2016 EDHS is not available as a public domain survey dataset. The authors requested access to the data from demographic, health survey program team and access was granted to use the data for this research.

\section{Acknowledgements}

I thankful to the Ethiopia demography and health survey coordinators for their assistant to give data. I also thankful to my family for the guidance given during the drafting of the 
document.

\section{Appendix}

Table 1. Frequency, percentage and chi square test of independent variables related to occurrence of diarrhea among under five children in Ethiopia.

\begin{tabular}{|c|c|c|c|c|c|}
\hline \multirow{2}{*}{ Variable } & \multirow{2}{*}{ category } & \multicolumn{2}{|c|}{ Occurrence of diarrhea } & \multirow{2}{*}{ Total } & \multirow{2}{*}{$\begin{array}{l}\text { Chi square test } \\
\text { (p-value) }\end{array}$} \\
\hline & & no & yes & & \\
\hline \multirow{4}{*}{ Region } & Tigray & $1776(33.3 \%)$ & $416(7.8 \%)$ & $2192(41.1 \%)$ & \multirow{4}{*}{0.000} \\
\hline & Amhara & $1260(23.6 \%)$ & $150(2.8 \%)$ & $1410(26.4 \%)$ & \\
\hline & Oromia & $521(9.8 \%)$ & $99(1.8 \%)$ & $620(11.6 \%)$ & \\
\hline & SNNP & $953(17.9 \%)$ & $160(2.9)$ & $1113(20.8 \%)$ & \\
\hline $\begin{array}{l}\text { Types of place of } \\
\text { residence }\end{array}$ & urban & $1369(25.7 \%)$ & $242(4.5 \%)$ & $1611(30.2 \%)$ & 0.557 \\
\hline \multirow{2}{*}{$\begin{array}{l}\text { Source of drinking } \\
\text { water }\end{array}$} & Unprotected & $1967(36.9 \%)$ & $415(7.7 \%)$ & $2382(44.6 \%)$ & \multirow{2}{*}{0.000} \\
\hline & Protected & $2543(47.7 \%)$ & $410(7.8 \%)$ & $2953(55.4 \%)$ & \\
\hline \multirow{3}{*}{ Age of households } & Less than 20 & $57(1.1 \%)$ & $8(0.15 \%)$ & $65(1.25)$ & \multirow{3}{*}{0.023} \\
\hline & $20-40$ & $2312(43.3 \%)$ & $383(7.2 \%)$ & $2695(50.5 \%)$ & \\
\hline & More than 40 & $2141(40.1 \%)$ & $434(8.1 \%)$ & $2575(48.2 \%)$ & \\
\hline Currently pregnant & no & $2132(40 \%)$ & $349(6.5 \%)$ & $2481(46.5 \%)$ & 0.009 \\
\hline \multirow{2}{*}{$\begin{array}{l}\text { Child live with } \\
\text { whom }\end{array}$} & respondents & $4289(80.4 \%)$ & $644(12.1 \%)$ & $4933(92.5 \%)$ & \multirow{2}{*}{0.000} \\
\hline & others & $221(4.1 \%)$ & $181(3.4 \%)$ & $402(7.5 \%)$ & \\
\hline \multirow{2}{*}{$\begin{array}{l}\text { Types of toilet } \\
\text { facility }\end{array}$} & No facility & $1131(21.2 \%)$ & $192(3.6 \%)$ & $1323(24.8 \%)$ & \multirow{2}{*}{0.270} \\
\hline & facility & $3379(63.3 \%)$ & $633(11.9 \%)$ & $4012(75.2 \%)$ & \\
\hline
\end{tabular}

Table 2. Binary logistic regression analysis for factors found to be associated with the occurrence of diarrhea among the age of under five children in Ethiopia.

\begin{tabular}{|c|c|c|c|c|c|c|}
\hline \multicolumn{2}{|c|}{ Had diarrhea recently } & \multirow[t]{2}{*}{ Odds ratio } & \multirow[t]{2}{*}{ Std. err } & \multirow[t]{2}{*}{$\mathbf{z}$} & \multirow[t]{2}{*}{$\mathbf{p}>|\mathbf{z}|$} & \multirow[t]{2}{*}{ 95\% Confidence interval } \\
\hline \multirow{3}{*}{ Region } & Region1 (Ref) & & & & & \\
\hline & Region 2 & 0.4687015 & 0.0500394 & -7.10 & 0.000 & 0.38020740 .5777929 \\
\hline & Region 4 & 0.7294543 & 0.0773537 & -2.97 & 0.003 & 0.59256220 .8979708 \\
\hline \multirow{3}{*}{$\begin{array}{l}\text { Source of } \\
\text { drinking water }\end{array}$} & Unprotected (Ref) & & & & & \\
\hline & protected & 0.7759161 & 0.0641573 & -3.07 & 0.002 & 0.65983050 .9124249 \\
\hline & $<20$ (Ref) & & & & & \\
\hline \multirow{2}{*}{$\begin{array}{l}\text { Age of } \\
\text { households }\end{array}$} & $20-40$ & 1.21048 & 0.4782584 & 0.48 & 0.629 & 0.55801972 .625825 \\
\hline & $>40$ & 0.4782584 & 0.5591397 & 0.88 & 0.378 & 0.65329473 .070437 \\
\hline \multirow{3}{*}{$\begin{array}{l}\text { Child lives with } \\
\text { whom } \\
\text { constant }\end{array}$} & Respondent (Ref) & & & & & \\
\hline & others & 5.951375 & 0.664595 & 15.97 & 0.000 & 4.7814867 .407501 \\
\hline & & 0.1697513 & 0.0669248 & -4.50 & 0.000 & 0.07838360 .3676217 \\
\hline
\end{tabular}

Note that: Ref=Reference category.

\section{References}

[1] Gidudu J, Sack D, Pina M, Hudson M, Kohl K, Bishop P et al: Diarrhea: case definition and guidelines for collection, analysis, and presentation of immunization safety data. Vaccine 2011, 29 (5): 1053-1071.

[2] Gedamu G, Kumie A, Haftu D. Magnitude and associated factors of diarrhea among under five children in Farta wereda, North West Ethiopia. Quality in Primary Care. 2017; 25 (4): 199-207.

[3] Kumar SG, Subita L. Diarrhoeal diseases in developing countries: a situational analysis. Kathmandu University Medical Journal. 2012; 10 (2): 83-8.
[4] Mengistie B, Berhane Y, Worku A. Prevalence of diarrhea and associated risk factors among children under-five years of age in Eastern Ethiopia: A cross-sectional study. Open Journal of Preventive Medicine. 2013 Oct 18; 3 (07): 446.

[5] Kasye DG, Garoma NH, Kassa MA. Assessment of the Prevalence of Diarrheal Disease Under-five Children Serbo Town, Jimma Zone South West Ethiopia. Clinics Mother Child Health. 2018; 15 (281): 2.

[6] Dessalegn M, Kumie A, Tefera W. Predictors of under-five childhood diarrhea: Mecha District, west Gojam, Ethiopia. Ethiopian journal of health development. 2011; 25 (3): 192200 .

[7] Bryce J, Boschi-Pinto C, Shibuya K, Black RE, WHO Child Health Epidemiology Reference Group. WHO estimates of the causes of death in children. The Lancet. 2005 Mar 26; 365 (9465): 1147-52. 
[8] Woldu W, Bitew BD, Gizaw Z. Socioeconomic factors associated with diarrheal diseases among under-five children of the nomadic population in northeast Ethiopia. Tropical medicine and health. 2016 Dec; 44 (1): 40.

[9] WHO/UNICEF. Why children are still dying and what to be done. Geneva, Switzerland. 2009; 12-29.

[10] Demographic E. Health Survey Central Statistical Agency Addis Ababa. Ethiopia ICF International Calverton, Maryland, USA. 2016

[11] Hosmer DW, Lemeshow S, Sturdivant RX. Introduction to the logistic regression model. Applied logistic regression. 2000; 2: $1-30$.

[12] Healy LM. Logistic regression: An overview. Eastern Michighan College of Technology. 2006 Mar 20.

[13] Agresti, A. (2002). An Introduction to Categorical data Analysis. $2^{\text {nd }}$ Edition, John Wiley and Sons. Inc., New York.

[14] Animut Alebel, Cheru Tesema, Belisty Temesgen, Alemu Gebrie, Pammla Petrucka, Getiye Dejenu Kibret. Prevalence and determinants of diarrhea among under-five children in Ethiopia: A systematic review and meta-analysis, 2018.

[15] Genet Gedamu, Abera Kumie, Desta Haftu. Magnitude and Associated Factors of Diarrhea among Under Five Children in Farta Wereda, North West Ethiopia, 2017.

[16] Hailemichael Bizuneh, Fentabil Getnet 2, Beyene Meressa, Yonatan Tegene and Getnet Worku. Factors associated with diarrheal morbidity among under-five children in Jigjiga town, Somali Regional State, eastern Ethiopia: a cross-sectional study, 2017.
[17] Amy J, Pickering, Jennifer D. Freshwater availability and water fetching distance affect child health in Sub-Saharan Africa. Environ Sci Technol 2012; 46: 2391-2397.

[18] Romahwati N, et al. Factors associated with diarrhea among under-five children in Banten province Indonesia, 2012. In: A secondary analysis of Indonesian national socio-economic survey 2007 and basic health research 2007: Health Res vol. 26 no. 1.

[19] Fazly Azry Abdul Aziz, Noor Ani Ahmad, Mohamad Aznuddin Abdul Razak, Maisarah Omar, Noraida Mohamad Kasim, Muslimah Yusof, Rajini Sooryanarayana, Rasidah Jamaludin and Chan Ying Ying. Prevalence of and factors associated with diarrhoeal diseases among children under five in Malaysia: a cross-sectional study, 2016.

[20] Mamo Z Degebasa, Dawit Zenebe. Weldemichael, Mokonnon $\mathrm{T}$ Marama. Diarrheal status and associated factors in under five years old children in relation to implemented and unimplemented community-led total sanitation and hygiene in Yaya Gulele, Ethiopia in 2017.

[21] Njuguna J. Effect of eliminating open defecation on diarrheal morbidity: improving sanitation and sustainable. An ecological study of Nambale sub-country, Kenya. BMC Public Health. 2016; 16: 712.

[22] Ogbeyi GO, Onyemocho A, Ogbonna C. Assessment of caregivers' knowledge of diarrhoea and practice of home management of diarrhoea disease among under two children in Opialu, a rural community in Benue state, Nigeria. Global Journal of Medicine and Public Health. 2016; 5 (2): 11. 